\title{
ALOKASI PORTOFOLIO OPTIMAL DENGAN METODE MOORE PENDROSE
}

\author{
ROZA RIA INDAH, DODI DEVIANTO \\ Program Studi Matematika, \\ Fakultas Matematika dan Ilmu Pengetahuan Alam, Universitas Andalas, \\ Kampus UNAND Limau Manis Padang, Indonesia, \\ roza.indah@ymail.com
}

\begin{abstract}
Abstrak. Salah satu permasalahan yang terjadi ketika seorang investor memutuskan untuk berinvestasi adalah bagaimana mendapatkan return yang diharapkan tetapi dengan risiko yang minimum. Implikasi dalam meminimumkan risiko adalah dengan menggunakan metode mean variance pada model Markowitz yang melibatkan matriks kovarian. Ketika matriks kovarian menghampiri matriks singular tetapi ill-conditioned, maka alokasi portofolio optimal dapat ditentukan dengan mengganti invers matriksnya dengan invers Moore Pendrose. Metode Moore Pendrose dapat diaplikasikan untuk menentukan alokasi portofolio pada 43 aset FTSE selama periode waktu terhitung sejak 1 Januari 2008 hingga 30 Desember 2014 yang datanya dapat diakses melalui http://yahoo.finance.com. Matriks kovarian dari aset tersebut menghampiri matriks singular, maka metode Moore Pendrose memberikan solusi yang lebih baik dalam menentukan alokasi portofolio optimal.
\end{abstract}

Kata Kunci: Matriks kovarian, ill-conditioned, invers Moore Pendrose, portofolio optimal

\section{Pendahuluan}

Investasi merupakan sebuah alternatif yang dapat digunakan untuk meningkatkan nilai aset dimasa mendatang. Orang yang melakukan investasi disebut investor. Setiap pilihan investasi mempunyai tingkat keuntungan (return) dan risiko (kerugian) yang berbeda. Oleh sebab itu, untuk melakukan investasi, investor harus mengetahui proses investasi, seperti waktu yang tepat untuk berinvestasi serta harus menentukan aset yang tepat untuk diinvestasikan agar tidak mengalami kerugian [5]. Untuk mengurangi risiko tersebut, investor perlu melakukan diversifikasi dengan membentuk portofolio aset yang merupakan gabungan atau kombinasi dari beberapa aset yang dimiliki investor.

Di bidang keuangan, implikasi untuk penentuan portofolio adalah matriks kovarian dari return aset. Penggunaan Matriks kovarian ini dimaksudkan untuk menentukan seberapa besar alokasi dana untuk masing-masing aset. Namun masalahnya adalah dalam penentuan alokasi dana tersebut diperlukan invers dari matriks kovarian tersebut, dan itu bisa saja tidak ada. Untuk menemukan solusi dari masalah ini, maka dapat digunakan metode pseudo invers atau invers Moore Penrose atau biasa juga disebut sebagai generalized inverse [5]. 


\section{Matriks Kovarian dan Invers Moore Pendrose}

Matriks kovarian adalah suatu matriks yang entri-entrinya adalah gabungan dari varian tiap variabel dan kovarian pada dua variabel yang berbeda. Matriks kovarian disimbolkan dengan $\Sigma$ yang dinyatakan seperti berikut [2]

$$
\begin{aligned}
\Sigma & =E\left[(X-\mu)^{\prime}(X-\mu)\right] \\
& =\left[\begin{array}{cccc}
\sigma_{1}^{2} & \sigma_{12} & \cdots & \sigma_{1 p} \\
\sigma_{21} & \sigma_{2}^{2} & \cdots & \sigma_{2 p} \\
\vdots & \vdots & \ddots & \vdots \\
\sigma_{n 1} & \sigma_{n 2} & \cdots & \sigma_{p}^{2}
\end{array}\right]
\end{aligned}
$$

dengan

$$
\begin{aligned}
\sigma_{j}^{2} & =\frac{\sum_{i=1}^{N}\left(x_{i j}-\mu_{j}\right)^{2}}{N}, \quad j=1,2, \cdots, p \\
\sigma_{j k} & =\frac{\sum_{i=1}^{N}\left(x_{i j}-\mu_{j}\right)\left(x_{i k}-\mu_{k}\right)}{N}, \quad j, k=1,2, \cdots, p
\end{aligned}
$$

dimana

$$
\begin{aligned}
\mu_{j} & =\text { rata-rata peubah ke- } j \\
\sigma_{j}^{2} & =\text { varian peubah ke- } j \\
\sigma_{j k} & =\text { kovarian peubah ke- } j \text { dan observasi ke- } k \\
N & =\text { banyaknya observasi } \\
x_{i j} & =\text { nilai pada observasi ke- } i \text { peubah ke- } j .
\end{aligned}
$$

Untuk mengetahui seberapa besar perubahan relatif (error) pada matriks kovarian tersebut, maka diperlukan suatu norm matriks $\Sigma$ yang berukuran $n \times n$ sebagai berikut [1]

$$
\|\Sigma\|=\max _{\|x\| \neq 0}\left(\frac{\|\Sigma x\|}{\|x\|}\right)
$$

dimana $\Sigma x$ adalah suatu vektor. Jika $x \in \mathbb{R}^{n}$, maka $\Sigma x \in \mathbb{R}^{n}$, sehingga $\|\Sigma\|$ adalah nilai terbesar dari norm vektor $\Sigma x, \forall x \neq \overrightarrow{0}$.

Teorema 2.1. [5] Norm matriks adalah pemetaan dari suatu fungsi terhadap setiap $x \in \mathbb{R}^{n \times n}$ yang disimbolkan dengan $\|A\|$ sedemikian sehingga memenuhi sifat-sifat berikut:

(i) $\|A\|>0$, untuk $A \neq 0$ atau $\|A\|=0$, untuk $A=0$

(ii) $\|\alpha A\|=|\alpha|\|A\|, \quad \alpha \in \mathbb{R}$

(iii) $\|A+B\| \leq\|A\|+\|B\|$

(iv) $\|A x\| \leq\|A\|\|x\|$

(v) $\|A B\| \leq\|A\|\|B\|$ 
Jika matriks kovarian diatas tidak memiliki solusi yang unik, maka dapat digunakan invers Moore Pendrose atau generalized inverse.

Definisi 2.2. [5] Invers Moore Pendrose dari suatu matriks A yang berukuran $m \times n$ adalah matriks yang berukuran $n \times m$ yang dinotasikan dengan $A^{+}$bila memenuhi sifat-sifat berikut:

(i) $A A^{+} A=A$

(ii) $A^{+} A A^{+}=A^{+}$

(iii) $\left(A A^{+}\right)^{\prime}=A A^{+}$

(iv) $\left(A^{+} A\right)^{\prime}=A^{+} A$

Misalkan $A$ merupakan suatu matriks berukuran $n \times n$, maka berlaku

$$
A \vec{x}=\vec{b}
$$

dimana $\vec{b}$ suatu vektor kolom yang berukuran $n \times 1$ dan $\vec{x}$ merupakan suatu solusi dari sistem persamaan linear, maka terdapat $\delta \vec{b}$ yang merupakan nilai error terkecil dari solusi persamaan tersebut, sehingga berlaku

$$
A \vec{x}^{\star}=\vec{b}+\delta \vec{b}
$$

sehingga dengan mensubstitusi persamaan (2.3) pada persamaan (2.4) diperoleh

$$
\begin{aligned}
A \vec{x}^{\star} & =A \vec{x}+\delta \vec{b} \\
A\left(\vec{x}^{\star}-\vec{x}\right) & =\delta \vec{b}
\end{aligned}
$$

Dengan demikian berlaku

$$
\frac{\left\|\vec{x}^{\star}-\vec{x}\right\|}{\|x\|} \leq\|A\|\left\|A^{-1}\right\| \frac{\|\delta \vec{b}\|}{\|b\|}
$$

Nilai $\|A\|\left\|A^{-1}\right\|=\kappa(A)$ menentukan seberapa besar perubahan relatif pada matriks $A$ dan nilainya disebut sebagai conditional number dari $A$.

Jika $\kappa(A)$ relatif kecil dari 1 (jika $A$ well-conditioned), maka perubahan relatif yang cukup kecil (error) pada $A$ tidak mengakibatkan perubahan relatif yang cukup besar pada inversnya, tetapi jika $\kappa(A)$ besar (jika $A$ ill-conditioned), maka perubahan relatif yang kecil (error) pada $A$ dapat mengakibatkan perubahan relatif yang besar pada inversnya [3].

\section{Portofolio Effisien dan Portofolio Optimal}

Dalam membentuk suatu portofolio, akan timbul suatu masalah. Permasalahannya adalah terdapat banyak sekali kemungkinan portofolio yang dapat dibentuk dari kombinasi aset berisiko yang tersedia. Kombinasi ini juga memasukkan aset bebas risiko didalam pembentukan portofolio. Jika terdapat kemungkinan portofolio yang jumlahnya terbatas, maka akan timbul pertanyaan portofolio mana yang akan dipilih investor. Jika investor rasional, maka mereka akan memilih portofolio optimal, yaitu portofolio yang mengkombinasikan aset berisiko dengan aset bebas risiko. 
Portofolio optimal dapat ditentukan dengan menggunakan model Markowitz. Untuk menentukan portofolio yang optimal dengan model tersebut, yang dibutuhkan adalah menentukan portofolio yang efisien. Portofolio yang efisien didefinisikan sebagai portofolio yang memberikan ekspektasi return terbesar dengan risiko tertentu.

Model Markowitz menggunakan asumsi-asumsi sebagai berikut:

(1) Waktu yang digunakan hanya satu periode

(2) Tidak ada biaya transaksi

(3) Preferensi investor hanya didasarkan pada ekspektasi return dan risiko dari portofolio

(4) Tidak ada pinjaman dan simpanan bebas risiko

Misalkan $w_{i}$ merupakan alokasi portofolio untuk aset ke- $i$, maka berlaku

$$
\Sigma_{i=1}^{N} w_{i}=1
$$

dan

$$
\overrightarrow{w^{\prime}} \vec{\mu}=q
$$

dengan $q$ merupakan ekspektasi return yang dibutuhkan dalam portofolio, maka dengan menggunakan definisi Markowitz dapat diasumsikan bahwa investor menginginkan portofolio dengan ekspektasi return dan risiko yang baik dengan cara berikut,

$$
\min \left(\sigma^{2}\right)=\min \left(\operatorname{var}\left(R_{p}\right)\right)=\min \left(\overrightarrow{w^{\prime}} \Sigma \vec{w}\right)
$$

dengan kendala

$$
\begin{aligned}
0 & \leq w_{i} \leq 1, \\
\overrightarrow{w^{\prime}} \overrightarrow{1} & =1 \\
\overrightarrow{w^{\prime}} \mu & =q\left(\min \mu_{i} \leq q \leq \max \mu_{i}\right), \text { dengan } i=1,2, \cdots, N .
\end{aligned}
$$

Untuk memperoleh nilai $\vec{w}$ yang dapat meminimumkan varian return portofolio dengan adanya kendala tersebut dapat diselesaikan dengan menggunakan metode Lagrange, sehingga diperoleh

$$
w=\frac{C-q B}{A C-B^{2}} \Sigma^{-1} \overrightarrow{1}+\frac{q A-B}{A C-B^{2}} \Sigma^{-1} \vec{\mu}
$$

Dengan demikian, persamaan (3.4) diatas dapat dijadikan solusi untuk menentukan alokasi portofolio optimal yang dapat meminimumkan varian atau risiko investasi yang mungkin dihadapi oleh investor.

Berdasarkan model Markowitz yang diperoleh pada persamaan (3.4) terlihat bahwasanya untuk penentuan alokasi portofolio bergantung pada invers dari matriks kovarian. Matriks kovarian ini bisa saja bersifat singular atau menghampiri singular tetapi ill-conditioned. Untuk mengatasi hal ini, maka penghitungan alokasi portofolio dapat dilakukan dengan metode Moore Pendrose atau generalized inverse atau biasa juga disebut sebagai pseudo inverse. Penggunaan metode ini dimaksudkan untuk meminimumkan nilai error pada invers tersebut dengan cara menyelidiki 
apakah nilai conditional number cukup besar atau tidak. Nilai conditional number yang cukup besar menyatakan perubahan relatif (error) pada matriks $\Sigma^{-1}$ cukup besar, sehingga untuk menga-tasinya dapat digunakan matriks $\Sigma^{+}$sebagai pengganti matriks $\Sigma^{-1}$. Dengan demikian, vektor pembobot alokasi dana untuk $N$ aset didalam portofolio dapat diduga seperti berikut

$$
w=\frac{C-q B}{A C-B^{2}} \Sigma^{+} \overrightarrow{1}+\frac{q A-B}{A C-B^{2}} \Sigma^{+} \vec{\mu}
$$

dengan:

$$
\begin{aligned}
& A=\overrightarrow{1^{\prime}} \Sigma^{+} \overrightarrow{1}, \\
& B=\overrightarrow{1^{\prime}} \Sigma^{+} \vec{\mu}=\overrightarrow{\mu^{\prime}} \Sigma^{+} \overrightarrow{1}, \\
& C=\overrightarrow{\mu^{\prime}} \Sigma^{+} \vec{\mu} .
\end{aligned}
$$

\section{Aplikasi Metode Moore Pendrose dalam Penentuan Portofolio Optimal}

Sebagai ilustrasi untuk mengaplikasikan metode Moore Pendrose dalam penentuan portofolio optimal dapat digunakan aset dari salah satu indeks pasar aset. Pada kasus ini hanya digunakan 43 aset dari indeks FTSE yang datanya lengkap selama periode waktu 1 Januari 2008 hingga 30 Desember 2014 dengan total 1823 observasi. Aset-aset dari indeks FTSE ini dapat diakses melalui http://yahoo.finance.com. Perhitungan diawali dengan mengurutkan data harga penutupan masing-masing aset dari yang data yang terlama hingga data yang terbaru. Kemudian dilakukan perhitungan return untuk masing-masing aset. Selanjutnya pembentukan portofolio diawali dengan menghitung nilai ekspektasi return untuk masing-masing aset dan kovarian untuk aset-aset tersebut tersebut dan kemudian data diurutkan berdasarkan nilai varian terkecil hingga terbesar.

Nilai ekspektasi return untuk masing-masing aset juga dapat dibuat dalam bentuk matriks seperti berikut

$$
\vec{\mu}=\left[\begin{array}{c}
E\left(R_{N G . L}\right) \\
E\left(R_{S S E . L}\right) \\
\vdots \\
E\left(R_{R B S . L}\right)
\end{array}\right]=\left[\begin{array}{c}
0,000215941898560 \\
0,000099528539560 \\
\vdots \\
0,005002063691017
\end{array}\right]
$$

dan terbentuk matriks kovarian $\Sigma$ dari returnnya dengan ukuran matriks $43 \times 43$ yang dapat dihitung dengan menggunakan persamaan (2.1) dan diperoleh hasil seperti berikut

$$
\Sigma=\left[\begin{array}{cccc}
0,000203935819570 & 0,000133372265107 & \cdots & 0,000108350250433 \\
0,000133372265107 & 0,000206141148589 & \cdots & 0,000143888774116 \\
\vdots & \vdots & \ddots & \vdots \\
0,000108350250433 & 0,000143888774116 & \cdots & 0,051953775771070
\end{array}\right]
$$

Sehingga, dari matriks kovarian diatas diperoleh $\operatorname{det} \Sigma=2,8352 \times 10^{-149}$, akibatnya dapat dikatakan bahwasanya matriks kovarian yang terbentuk dari 43 aset 
FTSE ini meghampiri singular. Untuk memeriksa nilai error dari invers matriks kovarian ini dapat digunakan dengan menghitung nilai condition number dan diperoleh hasil sebagai berikut

$$
\kappa(\Sigma)=\|\Sigma\|\left\|\Sigma^{-1}\right\|=6,2276 \times 10^{3} \approx 6 \times 10^{3}
$$

Tenyata $\kappa(\Sigma)$ yang diperoleh sekitar $6 \times 10^{3}$, maka kemungkinan perubahan relatif (error) pada solusi adalah sekitar enam ribu kali lebih besar dibandingkan perubahan relatif (error) pada $A$. Oleh sebab itu, matriks $A$ disebut sebagai matriks illconditioned.

Dengan demikian investor harus mempertimbangkan solusi yang tepat untuk mengalokasikan dana pada masing-masing aset. Untuk itulah investor perlu melakukan perbandingan antara perhitungan menggunakan invers $\left(\Sigma^{-1}\right)$ dengan pseudo invese $\left(\Sigma^{+}\right)$. Hasil yang diperoleh untuk masing-masing koefisien tersebut dapat dilihat pada tabel berikut.

Tabel 1. Perbandingan nilai koefisien A, B dan C antara metode invers dengan pseudo-invers

\begin{tabular}{|c|l|r|}
\hline. & Metode pseudo inverse $\left(\Sigma^{+}\right)$ & Metode invers $\left(\Sigma^{-1}\right)$ \\
\hline Nilai $A$ & $1,269988782593300 \times 10^{4}$ & $1,269988782593291 \times 10^{4}$ \\
Nilai $B$ & 3,636407473656985 & 3,636407473656965 \\
Nilai $C$ & 0,016068393116790 & 0,016068393116790 \\
\hline
\end{tabular}

Misalkan digunakan rate $q=0,028488$ sebagai tingkat ekspektasi return awal dan memplot grafik untuk memeriksa relasi antara ekspektasi return dan varian dari portofolio tersebut. Nilai ekspektasi returns dimulai dari interval $[0,028488$; $0,238488]$ dengan interval antar nilai $q$ adalah $i=0,005$.

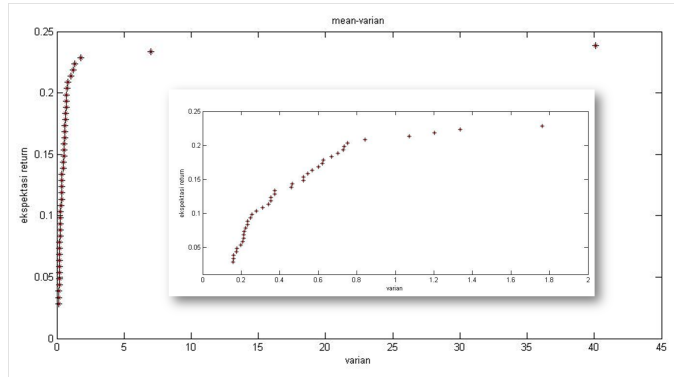

Gambar 1. Ekspektasi return vs Varian (Invers (red) dan pseudo inverse (black))

Dari Gambar 1, terlihat bahwasanya relasi antara ekspektasi return dan vari-an dari portofolio dengan menggunakan invers $\left(\Sigma^{-1}\right)$ dan pseudo inverse $\left(\Sigma^{+}\right)$hampir sama. Untuk mengetahui hasil mana yang memberikan return terbaik dengan risiko tertentu dapat dilihat dari nilai minimum norm alokasi portofolio $(w)$ untuk masingmasing aset tersebut. 
Perhatikan persamaan berikut

$$
\begin{aligned}
w & =\frac{C-q B}{A C-B^{2}} \Sigma^{-1} \overrightarrow{1}+\frac{q A-B}{A C-B^{2}} \Sigma^{-1} \vec{\mu} \\
\Rightarrow\|w\| \leq & \left(q(\|B\|+\|\vec{\mu} A\|)\left\|\frac{\Sigma^{-1}}{A C-B^{2}}\right\|\right)+\left((\|C\|+\|\vec{\mu} B\|)\left\|\frac{\Sigma^{-1}}{A C-B^{2}}\right\|\right)
\end{aligned}
$$

Akibatnya, dengan menggunakan persamaan diatas, diperoleh nilai alokasi portofolio dengan menggunakan invers $\left(\Sigma^{-1}\right)$ sebagai berikut

$$
\|w\| \leq(55223,58786324693 \times q)+25,200204594283871
$$

dan dengan mengganti $\Sigma^{-1}$ dengan $\Sigma^{+}$, maka diperoleh

$$
\|w\| \leq(55223,58786324700 \times q)+25,200204594283580
$$

Berdasarkan hasil yang diperoleh pada dua metode diatas terlihat bahwa hasilnya hampir sama. Norm pada alokasi portofolio $(\|w\|)$ menyatakan seberapa besar alokasi dana yang akan diberikan untuk masing-masing aset yang dimiliki oleh investor. Apabila nilai $\|w\|$ cukup besar, maka terdapat pengalokasian dana untuk beberapa aset yang nilainya cukup besar pula. Hal ini memberikan indikasi bahwasanya, jika aset tersebut mengalami kebangkrutan, maka investor akan mengalami kerugian yang cukup besar. Sedangkan pada $\|w\|$ yang relatif kecil, maka dapat dikatakan bahwasanya ekspektasi return untuk masing-masing aset terbagi secara merata, sehingga apabila salah satu aset mengalami kerugian, sedangkan aset lainnya mengalami keuntungan, maka investor tidak mengalami kerugian yang cukup besar. Mengingat nilai $\|w\|$ dengan menggunakan pseudo inverse yang diperoleh diatas lebih kecil dibandingkan dengan menggunakan invers, maka dapat dikatakan bahwasanya pengalokasian dana untuk masing-masing aset dengan metode Moore Pendrose terbagi secara merata dan dapat dijadikan alternatif bagi investor dalam membentuk portofolio yang optimal.

\section{Kesimpulan}

Tujuan utama dalam konsep manajemen portofolio adalah mengkombinasikan beberapa aset menjadi portofolio, yang mana hal ini dibutuhkan oleh investor, dan mengatur portofolio tersebut sedemikian rupa sehingga diperoleh ekpektasi return yang maksimum atas resiko yang mungkin terjadi. Untuk memperoleh ekpektasi return yang maksimum atas resiko yang mungkin terjadi, maka perlu diketahui terlebih dahulu hubungan mean-varian antar aset-aset yang akan dibentuk menjadi suatu portofolio, dimana mean menyatakan ekspektasi return dan varian menyatakan risiko yang mungkin dihadapi oleh investor. Untuk menurunkan risiko portofolio, maka investor perlu melakukan diversifikasi, dalam hal ini diversifikasi yang dilakukan adalah diversifikasi secara Markowitz yang melibatkan matriks kovarian $(\Sigma)$. Ketika matriks kovarian tersebut menghampiri singular, maka kemungkinan perubahan relatif (error) pada matriks tersebut cukup besar. Oleh sebab itu, terdapat suatu solusi yang dapat meminimumkan nilai perubahan relatif (error) tersebut, 
yaitu dengan metode Moore Pendrose. Metode ini menggunakan pseudo invers matriks kovarian $\left(\Sigma^{+}\right)$sebagai pengganti invers matriks kovarian $\left(\Sigma^{-1}\right)$.

\section{Daftar Pustaka}

[1] Gentle, J.E. 1998. Numerical Linear Algebra for Applications in Statistics. Fairfax, Virginia

[2] Johnson, R.A and D.W. Wichem. 2007. Applied Multivariate Statistical Analysis. Sixth Edition. Pearson Education, Inc, United State of America

[3] Meyer, C.D. 2000. Matrix Analysis and Applied Linear Algebra. SIAM

[4] Olivier, Ledoit. Improved estimation of the covariance matrix of stock returns with an application to portfolio selection. Journal of Empirical Finance, pp 603 $-621$

[5] Schoot, J.R. 1997. Matrix Analysis for Statistics. A Wiley Interscience Publication, New York 